\title{
Antropofagias Tecnocientíficas: devorando algumas ideias
}

\author{
Eduardo Nazareth Paiva ${ }^{1}$ \\ ${ }^{1}$ Programa de Pós-Graduação em História das Ciências e das Técnicas e Epistemologia \\ (HCTE), Universidade Federal do Rio de Janeiro \\ edu@hcte.ufrj.br \\ Recebido: 26/11/2019 Aceito: 8/12/2019 Publicado: 12/12/2019
}

\begin{abstract}
If you were tempted to devour technological gaps around you with any pedagogy of hope, and someone arrogantly might have said: don't hold your breath. Or if you still want to insist, someone might say go jump in the lake. Don't be upset, be it culturally and metaphorically anthropophagic: wait while sitting on the sculpture "After the Bath", carved in soapstone by the Swedish artist Pye Engström, located in Stockholm, Sweden. In this sculpture, an enigmatic and controversial couch, "until now", Brazilian educator Paulo Freire is portrayed sitting next to Swedish-Norwegian journalist and sex educator Elise Ottesen-Jensen, next to Swedish author and public debater Sara Lidman, near to Chinese Communist leader Mao Zedong, close to American scholar, close to human rights activist and feminist Angela Davis, to Swedish American scholar and environmentalist Georg Borgström and Chilean poet, diplomat and politician Pablo Neruda. Pulling Bishop Sardinha to our side, Chico Cesar praised our greatest technoscientific inventor: Alberto Santos Dummond was the father of aviation, hovering between man and god, an angel who rose between the ground and the sky to see what it is. good, soared in the sky on a paper plane, flying with one hand, the other saying goodbye.
\end{abstract}

Keywords: Anthropophagy. Oswaldian. Technoscience. Brazilian.

Resumo. Se você estiver tentado a devorar os gaps tecnocientíficos que nos rodeiam com alguma pedagogia da esperança, e se alguém mais arrogante mandar você esperar sentado ou tomar banho, deixo aqui uma sugestão antropofágica: espere sentado na escultura "Depois do Banho", esculpida em pedra-sabão pelo artista sueco Pye Engström, localizada em Estocolmo na Suécia. Nesta escultura, um enigmático e controverso sofá, "so far way", o educador brasileiro Paulo Freire é representado sentado ao lado da jornalista e educadora sexual norueguesa-sueca Elise OttesenJensen, da autora e debatedora pública sueca Sara Lidman, do líder comunista chinês Mao Tsé-Tung, da acadêmica americana, ativista de direitos humanos e feminista Angela Davis, do acadêmico e ambientalista sueco-americano Georg Borgström e do poeta, diplomata e político chileno Pablo Neruda. Puxando o Bispo Sardinha para o nosso lado, Chico César, em estado de poesia terapêutica, exaltou nosso maior inventor: Alberto Santos Dummond foi papai da aviação, pairando entre o homem e deus, um anjo que ascendeu entre o chão mais chã e o céu, para ver o que é bom, subiu ao céu num avião de papel, pilotando só com uma mão, com a outra dando adeus.

Palavras-chave: Antropofagia. Oswaldiana. Tecnociência. Brasileira. 


\section{Informações gerais}

Só me interessa o que não é meu.

(Manifesto Antropófago, 1928)

Quando nos vemos no Brasil, inserido num lugar latino-americano, percebemos uma produção e distribuição, cada vez maior, dos chamados "avanços da tecnociência" com um, também cada vez maior, distanciamento entre o que é chamado de estado da arte e às formas de acesso a esses novos recursos e soluções, na maioria das vezes, oriundos dos chamados centros de concepção (em geral, Europa e Estados Unidos da América).

A chegada e difusão destes "avanços" em nosso país e região são pautadas de fora pra dentro e, mesmo diante de todas as nossas limitações, via de regra, estas agendas de uso e dependência são aceitas e consideradas como sendo "naturais" ou "razoáveis" dentro dos preceitos "universalmente" aceitos, de busca da melhoria dos padrões de "qualidade de vida" no mundo moderno. Esta controversa receita de futuro pode incluir ingredientes como o "darwinismo social" (MOGILSKI, 2016), "determinismo tecnológico” (MONTOYA, 2004), “determinismo histórico-social” (KATZ, 1998), etc.

Esta conjuntura de prenúncios dos efeitos globalizantes e da chegada do tempo histórico do antropoceno tem sido alvo do interesse de diversos autores como, por exemplo, Raymond Williams, em seu clássico livro sobre a televisão:

Costuma-se dizer que a televisão alterou o nosso mundo. Da mesma forma, as pessoas costumam falar de um novo mundo, de uma nova sociedade, de uma nova fase da história sendo criada -'provocada'- por essa ou aquela nova tecnologia: a máquina a vapor, o automóvel, a bomba atômica. A maioria de nós sabe o que geralmente está implícito quando essas coisas são ditas. Mas esta pode ser a dificuldade central: nos acostumamos a declarações desse tipo em nossas discussões mais comuns e assim podemos deixar de perceber seus significados específicos. (WILLIAMS, 2003)

Na mesma pegada da difusão, da televisão à Internet, podemos perceber no nosso cotidiano as declarações e discussões desses chamados "avanços". Seguem exemplos:

- Telefonia $5 \mathrm{G}$

"PREPARE-SE PARA A TELEFONIA 5G

Como a quinta geração das redes de celulares transformará setores inteiros da economia - e afetará a vida de todos nós" https://epoca.globo.com/prepare-se-para-telefonia-5g-23930453

- Carros Elétricos

"Falta democratizar o carro elétrico como fizeram com o celular, diz executivo da Nissan"

https://www.ecommercebrasil.com.br/noticias/futuro-setor-automobilistico/

Nossos gaps tecnocientíficos afetam de forma direta tudo aquilo que possamos chamar de local. Atualmente, diante da ubiquidade do que é tecnocientífico, em termos gerais, 
parece que tudo que é local está fadado a ser condenado, de forma irreversível, à obsolescência. Na dúvida, olhe ao seu redor e observe as suas companhias do seu cotidiano. Para não ir muito longe, observe à sua volta os computadores, os meios de comunicação e transporte.

Quem vos faz companhia são as companhias dos outros, de fora.

Como conviver com esta situação e condição de, cada vez mais, se ver distante de uma utópica autonomia tecnocientífica brasileira? Como isso produz efeitos sobre nossas cidadanias e sobre nossas opções?

Segundo Darcy Ribeiro:

O Brasil é já a maior das nações neolatinas, pela magnitude populacional, e começa a sê- lo também por sua criatividade artística e cultural. Precisa agora sê- lo no domínio da tecnologia da futura civilização, para se fazer uma potência econômica, de progresso auto- sustentado. (RIBEIRO, 1995, p.455)

Assistimos a um processo de substituição do local pelo global, com estabelecimento de hegemonias, de ubiquidades, de irreversibilidades ditadas por artefatos, serviços e políticas tecnocientíficas globais que jogam na obsolescência tudo aquilo que um dia chamamos de local.

Essa quase que escatologia tecnológica conversa com as ideias Schumpterianas, cheias de fúrias, destruições, tempestades e tormentas:

Velhas firmas e indústrias tradicionais, estejam ou não diretamente expostas à fúria dos elementos, vivem ainda assim em meio da eterna tempestade. Surgem, no processo da destruição criadora, situações em que muitas firmas que afundam teriam podido continuar a navegar vigorosa e utilmente se tivessem podido atravessar determinada tormenta. (SCHUMPETER, 1961, p.117-118).

Para tentar dar conta desses dilemas da hegemonia do global sobre o local, lançarei mão de uma frente epistêmica denominada pensamento antropofágico.

\section{O Pensamento Antropofágico}

"Antes dos portugueses descobrirem o Brasil, o Brasil tinha descoberto a felicidade"

(Manifesto Antropófago, 1928)

O Pensamento Antropofágico tem na Semana de Arte Moderna de 1922, digamos assim, a sua pedra fundamental. Ali, alguns dos artistas participantes desse movimento cultural brasileiro defenderam um rompimento radical com a arte eurocentrada, em vigência na época e, porque não dizer, desde nosso "descobrimento". Este movimento cultural brasileiro, também sintetizado como Antropofagia, teve também como marcos de sua criação as importantes publicações do Manifesto da Poesia Pau-Brasil, publicado no Correio da Manhã em 18 de março de 1924, e do Manifesto Antropófago, de Oswald de Andrade no primeiro número da Revista de Antropofagia (Ano I, No. I - 05/1928). 
Encontramos no Manifesto Antropófago(1928):

Só a ANTROPOFAGIA nos une. Socialmente. Economicamente. Filosoficamente. Única lei do mundo. Expressão mascarada de todos os individualismos, de todos os coletivismos. De todas as religiões. De todos os tratados de paz. Tupi, or not tupi that is the question. Contra todas as catequeses. E contra a mãe dos Gracos. Só me interessa o que não é meu. Lei do homem. Lei do antropófago.

Outro importante símbolo do Movimento Antropofágico é o quadro Tarsila do Amaral de nome Antropofagia (1928-1930). Tarsila do Amaral produz neste quadro a fusão de dois outros importantes quadros seus: "A Negra" e o "Abaporu" - "homem que come gente" (canibal ou antropófago) é uma junção dos termos aba (homem), pora (gente) e ú (comer) é uma espécie de símbolo do movimento antropofágico.

Ainda como explicação das ideias antropofágicas, em especial das suas características e potências metafóricas, diagnósticas e terapêuticas, segue o texto de Benedito Nunes:

Como símbolo da devoração, a Antropofagia é, a um tempo, metáfora, diagnóstico e terapêutica: metáfora orgânica, inspirada na cerimônia guerreira da imolação pelos tupis do inimigo valente apresado em combate, englobando tudo quanto deveríamos repudiar, assimilar e superar para a conquista de nossa autonomia intelectual; diagnostico da sociedade brasileira como sociedade traumatizada pela repressão colonizadora que lhe condicionou o crescimento, e cujo modelo terá sido a repressão da própria antropofagia ritual pelos Jesuítas, e terapêutica, por meio dessa reação violenta e sistemática, contra os mecanismos sociais e políticos, os hábitos intelectuais, as manifestações literárias e artísticas, que, até a primeira década do século XX, fizeram do trauma repressivo, de que a Catequese constituiria a causa exemplar, uma instância censora, um Superego coletivo. Nesse combate sob forma de ataque verbal, pela sátira e pela crítica, a terapêutica empregaria o mesmo instinto antropofágico outrora recalcado, então liberado numa catarse imaginária do espírito nacional. E esse mesmo remédio drástico, salvador, serviria de tônico reconstituinte para a convalescença intelectual do país e de vitamina ativadora de seu desenvolvimento futuro. A jocosa alternativa do dilema hamletiano parodiado - Tupy or not tupy, that is the question - que parece ter sido a célula verbal originária do Manifesto, resolve-se pois numa rebelião completa e permanente. (NUNES, 1970, p. 25-26) 


\section{A Tecnociência}

Tínhamos Política que é a ciência da distribuição. (Manifesto Antropófago, 1928)

O termo tecnociência tem sido, cada vez mais, empregado por aqueles interessados nas questões envolvendo a ciência, a tecnologia e os artefatos produzidos no encontro das ciências com as tecnologias.

Segundo Bernadette Vincent e Sacha Loeve:

O termo "tecnociência" ganhou importância filosófica na década de 1970, mas despertou visões ambivalentes. Por um lado, vários estudiosos o usaram para lançar luz sobre características específicas de pesquisas científicas recentes, especialmente no que diz respeito às tecnologias emergentes que obscurecem fronteiras (como natural / artificial, máquina / ser vivo, conhecimento / fabricação e assim por diante); por outro lado, a "tecnociência" não suscitou grande interesse entre os filósofos. $\mathrm{Na}$ área francesa, prevalece um significado depreciativo: "tecnociência" que significa a contaminação da ciência pela administração e pelo capitalismo. Alguns até argumentam que "tecnociência" não é um conceito, mas sim apenas uma palavra de ordem. (VINCENT, \&LOEVE, 2018).

O termo tecnociência é controverso. Nas palavras de Alfred Nordmann:

Entre os filósofos da ciência, o uso do termo "tecnociência" sofreu sua afiliação, especialmente com Bruno Latour e Donna Haraway. Nos últimos anos, no entanto, o termo difundiu-se e não pode mais ser associado a tradições intelectuais particulares. A reticência em adotar esse termo baseia-se em uma suspeita específica: "Tecnociência" implica uma dissociação de uma "ciência" idealizada e, assim, lança dúvidas sobre a pertinência dos valores associados à ciência - os valores associados ao Iluminismo, normas Mertonianas, racionalismo crítico, desinteressada busca da verdade, representação teórica de como as coisas realmente são etc. Existe uma suspeição de que a escolha do termo "Tecnociência", como conceito interpretativo mais apropriado, corresponde ao seu endosso e, portanto, também a uma rejeição triunfante dos valores da ciência que agora estariam expostos como obsoletos (NORDMANN, 2010).

Adotarei uma visão da tecnociência compartilhada dentro do coletivo de pensamento dos Estudos de Ciência, Tecnologia e Sociedade. De acordo com Ivan da Costa Marques:

A palavra tecnociência designa todo o conjunto de atividades percebidas pelos que estudam a "ciência tal como ela é feita", isto é, atividades que explicam / participam da construção dos conhecimentos científicos e tecnológicos. (MARQUES, 2011).

\section{Antropofagias Tecnocientíficas}

Já tínhamos o comunismo. 


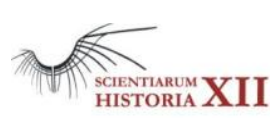

(Manifesto Antropófago, 1928) A combinação das palavras e sentidos dos movimentos culturais associados à antropofagia e a tecnociência em suas potenciais metáforas, diagnósticos e terapêuticas apresenta diversos desafios incluindo aqueles da hegemonia do Global sobre o Local.

O enfrentamento desses desafios talvez devesse ser feito com base nos chamados Estudos Decoloniais ou Fronteiriços (MIGNOLO, 2003), (PALERMO\&QUINTERO, 2014) e mesmo se utilizando de recursos metodológicos como aqueles encontrados no Programa Forte (BLOOR, 1991) ou mesmo no Princípio de Simetria Generalizado (LATOUR, 2013). Para ilustrar a complexidade das relações entre as ideias do Movimento Antropofágico e as opções possíveis para a Tecnociência Brasileira sugiro assistir ao vídeo de título: "Conhecimentos Brasileiros e Antropofagia", apresentado pelo Pesquisador e Professor Ivan da Costa Marques (MARQUES, 2019).

Mas, aqui nesta comunicação, procurarei uma síntese semiótica que busque transmitir ideias e reflexões sintéticas. Neste exercício de representação sintética que se aproximará da poesia visual, ficará óbvia a influência dos aforismos oswaldianos, das expressões artísticas da pintura de Tarsila do Amaral, Paulo Bruscky, Gregório de Matos, das composições de Bezerra da Silva, Marcelo D2, Chico César, Antônio Sérgio Mendonça Álvaro Sá entre outros. Uma miscigenação e justaposição de heterogêneos. Esta síntese poética visual está representada na Figura 1, pronta para ser devorada.

\section{Conclusões}

A gente escreve o que ouve, nunca o que houve (Oswald de Andrade - Serafim Ponte Grande)

O trabalho explorou uma reflexão antropofágica sobre nosso tempo histórico, marcado pela tecnociência, a partir de uma análise conceitual e de uma síntese através de uma meta poesia visual (Figura 1). Nesta representação se fez uma bricolagem com inspirações tais como aquelas encontradas no Manifesto da Poesia do Pau-Brasil (1924). Ali, como aqui, se tentou fazer "o trabalho contra o detalhe naturalista - pela síntese; contra a morbidez romântica - pelo equilíbrio geômetra e pelo acabamento técnico; contra a cópia, pela invenção e pela surpresa". Devorar o estrangeiro e misturá-lo com guaraná, mate, samba, tropicália, caipirinha, feijoada, pau-brasil, ipê, Fenemê, Embraer, Petrobras e o escambau. A representação sintética foi inspirada no Manifesto Antropófago (1928) para com ele enfrentar dilemas tais como: "Tupi, or not tupi that is the question". Explorando: "A magia e a vida. Tínhamos a relação e a distribuição dos bens físicos, dos bens morais, dos bens dignários (possivelmente, dignitários). E sabíamos transpor o mistério e a morte com o auxílio de algumas formas gramaticais". Parafraseando Bezerra da Silva: Se Leonardo da Vinci porque eu não posso $\mathrm{D} 2$ ? 


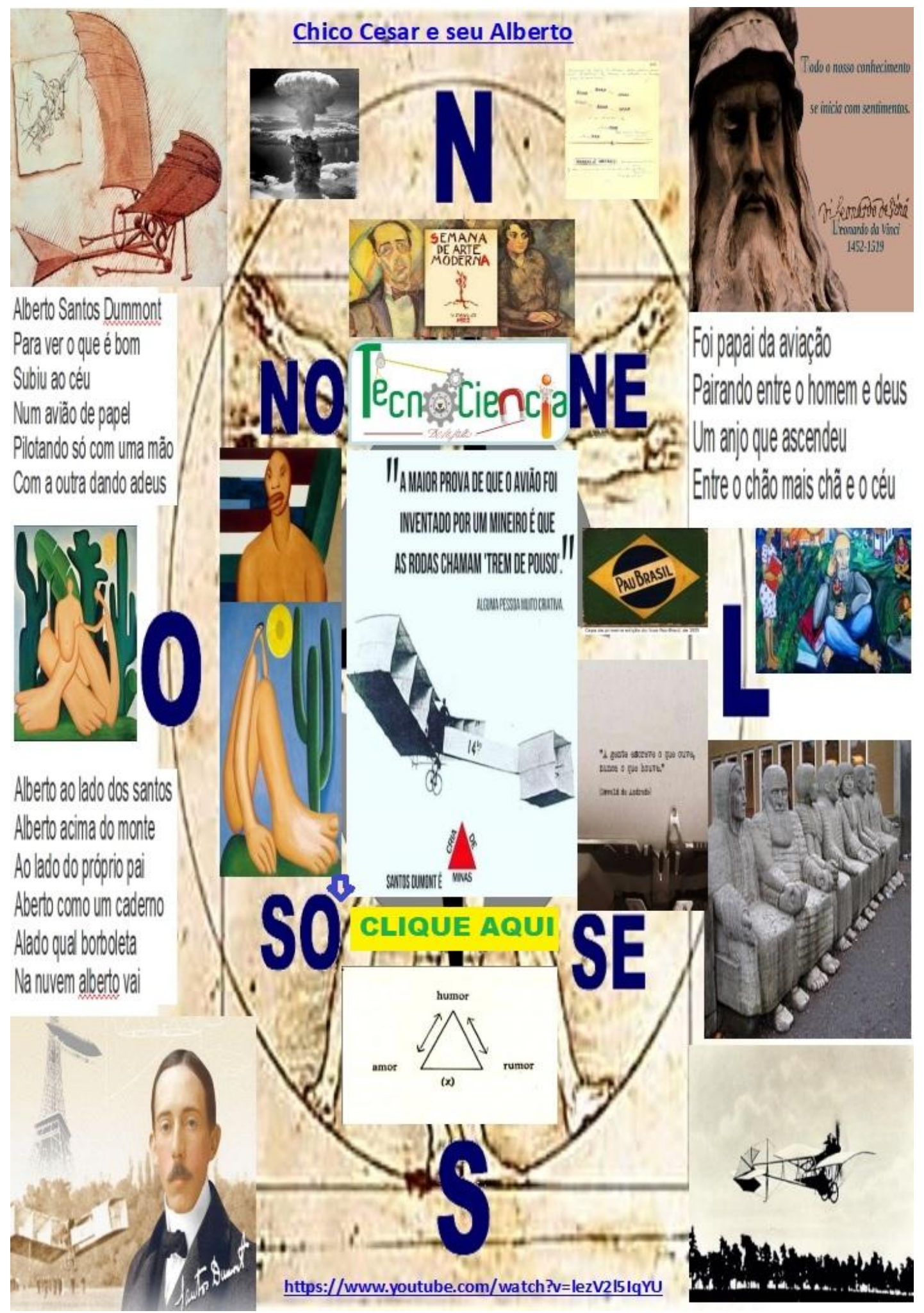

Figura 1: Poesia visual de uma antropofagia tecnocientífica 


\section{Financiamento}

O presente trabalho foi realizado com apoio da Coordenação de Aperfeiçoamento de Pessoal de Nível Superior - Brasil (CAPES) - Código de Financiamento 001.

\section{Referências}

BLOOR, D. Knowledge and Social Imagery. University of Chicago Press, 1991.

CÉSAR, Chico. Alberto. Estado de Poesia. https://youtu.be/sYq6M4KHzhI (2015).

KATZ, Claudio. Determinismo tecnológico y determinismo histórico-social. Redes, vol. V, núm. 11, junio, 1998, pp. 37-52. Acesso Internet em 24/11/2019: http://www.redalyc.org/articulo.oa?id=90711314002. Buenos Aires, Argentina.

LATOUR, B. Jamais fomos modernos: Ensaio de Antropologia Simétrica. Tradução de Carlos Irineu da Costa. São Paulo: Editora 34, 2013.

MARQUES, I. C. Localizando o global e redistribuindo o local. Anais da IX Congresso Brasileiro de História Econômica e 10 a Conferência Internacional de História de Empresas. Curitiba, PR: ABPHE Universidade Federal do Paraná, 2011. v. 1. p. 1-24.

MARQUES, I. C. Conhecimentos Brasileiros e Antropofagia. Acesso em: 24/11/2019: <https://youtu.be/Ci7D8H6F-yw $>$.

MIGNOLO, W. D. Historias Locales / Disenos Globales: Colonialidad, Conocimientos Subalternos Y Pensamiento Fronterizo. Cidade do México: Ediciones Akal Sa, 2003.

MOGILSKI, Justin. Social Darwinism. T.K. Shackelford, V.A. Weekes-Shackelford (eds.), Encyclopedia of Evolutionary Psychological Science, Springer International Publishing Switzerland. 2016.

MONTOYA Suárez, Omar. Schumpeter, innovación y determinismo tecnológico. Scientia et technica, [S.1.], v. 2, n. 25, ago. 2004. ISSN 2344-7214. Disponible en: <http://revistas.utp.edu.co/index.php/revistaciencia/article/view/7255/4285>. Acesso Internet: 24 nov. 2019 doi:http://dx.doi.org/10.22517/23447214.7255

NORDMANN, Alfred. Science in the Context of Technology. In Martin Carrier and Alfred Nordmann (eds.). Dordrecht: Springer, 2010, pp. 317-336.

NUNES, B. Antropofagia ao Alcance de Todos. In: ANDRADE, O. D. Obras completas de Oswald de Andrade (1890-1954). Rio de Janeiro: Editora Civilização brasileira, 1970. Coleção Vera Cruz. Literatura brasileira, v. 147.

PALERMO, Z.; QUINTERO, P. (Eds.). Aníbal Quijano: Textos de fundación. [S.1.]: Ediciones del Signo, 2014. Prefácio de Walter Mignolo.

RIBEIRO, Darcy. O Povo Brasileiro: a Formação e o Sentido do Brasil. Editora: Companhia das Letras. São Paulo. 1995

SCHUMPETER, Joseph A. Capitalismo, Socialismo e Democracia. Editora Fundo de Cultura. Rio de Janeiro. 1961.

VINCENT, B. LOEVE, S. Toward a Philosophy of Technosciences. In Loeve, S. Guchet X., \& Bensaude Vincent B. (eds.). Acesso Internet em 24/11/2019: https://hal.archives-ouvertes.fr/hal01820186/document. Springer, pp. 169-186. 2018. 
WILLIAMS, R. Television: Technology and Cultural Form, ed. E. Williams, Routledge Classics edition obra baseada na primeira edição de 1974 - London and New York: Routledge, 2003. 